Jarosław JAKIELASZEK

(Warszawa, UW)

\title{
PERYFRAZA PROGRESYWNA I STRATEGIE TEKSTOWE
}

Na podstawie Moriundum esse pro Dei Filio Lucyfera z Cagliari

Zgodnie $\mathrm{z}$ powszechnie przyjętą opinią, jedną z charakterystycznych cech sermo vulgaris jest tendencja do wprowadzania i rozszerzania zakresu użycia konstrukcji analitycznych. Ten proces rozwojowy, śledzony od Plauta poczynając, zaowocował stanem widocznym w językach romańskich - eliminacją form syntetycznych widoczną zwłaszcza w obrębie kategorii nominalnych. W wypadku kategorii czasownikowych sytuacja jest bardziej złożona, choć i tu nie ulega wątpliwości zdecydowany wzrost znaczenia konstrukcji analitycznych (także tych, które w efekcie dały nowe formy syntetyczne). Nie może zatem dziwić, że obecność konstrukcji analitycznych interpretuje się często jako nieomylny symptom wpływu sermo vulgaris na język jakiegoś autora antycznego. Jedna z syntagm, traktowanych często jako wskaźnik obecności elementów potocznych, jest peryfrastyczna konstrukcja participum praesentis activi (p.p.a.) + esse, której występowanie ma być efektem rzekomo cechującej język potoczny tzw. tendencji analitycznej. Autorem, u którego obecność tej konstrukcji jest szczególnie często podnoszona jako charakterystyczna dla stylu, jest biskup polemista, gorący obrońca Wiary Nicejskiej - Lucyfer z Cagliari $(† 371)$. Jakkolwiek jego język był wielokrotnie analizowany ${ }^{1}$, to zgodność osiągnięto jedynie co do uznania peryfrazy za jedną z cech charakterystycznych jego stylu, a stan badań na ten temat dobrze podsumowuje konkluzja A. Pirasa: „La predilezione del Nostro Autore per questa perifrasi, che lo distingue dagli altri autori, sebbene s'inserisca nella generale ipertrofia sintattica propia di Lucifero, resta peraltro senz' una spiegazione sicura"2. Jako przykład na zastosowanie tej konstrukcji może posłużyć następujące zdanie z Moriundum esse pro Dei Filio:

„Nos sumus tantum sacras scientes litteras"3.

${ }^{1}$ Por. np. G. Diercks, Les formes verbales périphrastiques dans les auvres de Lucifer de Cagliari, w: Corona Gratiarum. Miscellanea Eligio Dekkers oblata, Brugge 1975, 139-150.

${ }^{2}$ Por. A. Piras, Sul latino di Lucifero di Cagliari, VetCh 29 (1992) 315-343.

${ }^{3}$ Lucifer Calaritanus, Moriundum esse pro Dei Filio 11, 17, CCL 8, 288. 
Zjawisko występowania peryfrazy p.p.a. + esse w tekstach Lucyfera należy rozpatrywać zarówno jako składniowo-semantyczne, jak i stylistyczne, a przytoczony wyżej fragment jest w związku $\mathrm{z}$ tym ostatnim aspektem nader istotny. Konstrukcje składające się z p.p.a. + esse obejmują szereg składniowych konfiguracji strukturalnych. Za peryfrazy właściwe uznać można jedynie takie przykłady, w których oba elementy analizować trzeba jako nieciągły wykładnik morfologiczny jednej funkcji gramatyczno-semantycznej. Wzmiankując częste występowanie p.p.a. + esse u Lucyfera, E. Löfstedt sugeruje analogię $\mathrm{z}$ angielskimi formami $\mathrm{z}$ grupy continuous, dostrzegając możliwość semantycznego zróżnicowania peryfrazy i form syntetycznych ${ }^{4}$.

Semantyka form progresywnych stała się przedmiotem wielu badań, modyfikujących i rozszerzających fundamentalne propozycje D. Dowty'ego ${ }^{5}$. Podstawa analizy jest uznanie form progresywnych za inkorporujące operator progresywności, element semantyczny zawierający odniesienie do światów możliwych ${ }^{6}$. Podstawową zaletą takiego podejścia jest uchwycenie modalnego aspektu form progresywnych (dzięki ograniczeniu światów do należących jedynie do kontekstu, wyznaczanego przez modalną relację dostępności). Operator progresywności jest zatem składnikiem semantycznym niezależnym od semantycznego czasu, a od aspektu semantycznego odróżnia go - wspólny z operatorem przyszłości - element modalny. Morfologiczna realizacja różnych kombinacji czasu, aspektu i pozostałych składników systemu modalnoczasowo-aspektowego nie jest jednoznacznie zdeterminowana cechami semantycznymi i wykazuje silną zmienność diachroniczną. W szczególności, progresywność nie ma w systemie okresu klasycznego stabilnego, wyspecjalizowanego wykładnika morfologicznego, pozostając zazwyczaj bez refleksu powierzchniowego. Dobrze widoczne jest to w imperfectum (niekiedy - niesłusznie progresywność bywa uważana za charakterystyczną cechę imperfectum), występuje jednak również w praesens. Progresywny walor peryfrazy szczególnie wyraźny jest $w$ przypadku skontrastowania $z$ perfectum:

„Haec iam tu fecisti atque es faciens"?.

„Si sapiens es, cur ea fecisti atque es faciens, quod soli possunt facere insipientes?"8

${ }^{4}$ Por. E. Löfstedt, Philologischer Kommentar zur Peregrinatio Aetheriae, Uppsala 1911, 248.

${ }^{5}$ Por. D. Dowty, Word Meaning and Montague Grammar, Dordrecht - Reidel 1979.

${ }^{6}$ Następująca definicja operatora progresywności ujmuje najważniejsze konsekwencje semantyczne jego obecności w strukturze: $\lambda$ P. $\lambda \mathrm{e}$. $\lambda \mathrm{t}$. $\lambda \mathrm{w}$. $\forall \mathrm{w}^{\prime} \forall \mathrm{t}^{\prime}\left[\mathrm{R}(\mathrm{w})\left(\mathrm{w}^{\prime}\right) \& \mathrm{t} \mathrm{t}^{\prime} \subset \mathrm{t} \rightarrow(\mathrm{e}) \subset \mathrm{t}^{\prime} \&\right.$ $\left.\mathrm{P}(\mathrm{e})\left(\mathrm{t}^{\prime}\right)\left(\mathrm{w}^{\prime}\right)\right]$. Por. także: T. Parsons, The Progressive in English: Events, States and Processes, "Linguistics and Philosophy” 12 (1989) 213-241; F. Landman, The Progressive, „Natural Language Semantics" 1 (1992) 1-32; A. Bonomi, The Progressive and the Structure of Events, „Journal of Semantics" 14 (1997) 173-205; tenze, Semantical remarks on the progressive reading of the imperfective, Milano 2002 (ms.); J. Higginbotham, The English Progressive, w: J. Guéron - J. Lecarme (ed.), The Syntax of Time, Cambridge Mass. 2004, 329-358.

${ }_{7}$ Lucifer Calaritanus, De non parcendo in Deum delinquentibus 31, 21, CCL 8, 254.

${ }^{8}$ Tenże, De Athanasio sive Quia absentem nemo debet iudicare nec damnare II 6, 2-3, CCL 8, 86 . 
Perfectum realizuje tu kompleks semantycznego czasu przeszłego i aspektu perfektywnego (PAST+PFV), peryfraza progresywna natomiast czasu teraźniejszego i operatora progresywności (PRES+PROG) ${ }^{9}$.

Hipoteza semantycznej ekwiwalencji peryfrazy p.p.a. + esse i form progresywnych sprowadza się zatem do założenia, że paradygmat werbalny zostaje wzbogacony o odrębny, nieciągły wykładnik cech semantycznych, skądinąd obecnych już $w$ języku. To stwierdzenie istotne wobec systematycznie ponawianych przypuszczeń o obcym systemowo charakterze konstrukcji peryfrastycznej, zmierzających do przypisania jej obcego pochodzenia jako hellenizmowi, a zasadniczo biblizmowi (ostatecznie zatem pośredniemu semityzmowi) ${ }^{10}$. U źródła takich sugestii tkwi spostrzeżenie uderzającej częstości zgramatykalizowanej peryfrazy w tekstach biblijnych, wsparte przykładami odpowiedniości p.p.a. w Septuagincie i konstrukcji imiesłowowej tekstu hebrajskiego. Dla obecności konstrukcji peryfrastycznej w greckim tekście Nowego Testamentu, przyjmuje się bądź bezpośredni wpływ semicki, bądź imitację języka LXX (lub oba te czynniki równocześnie), z implikacją wpływu na język tekstu łacińskiego wedhug Wulgaty ${ }^{11}$ :

„Erat autem rex Salomon regnans super omnem Israel” (3Reg 4, 1).

"Erat enim docens eos sicut potestatem habens" (Matth 7,29).

„Erant autem illic quidam de scribis sedentes et cogitantes in cordibus suis" (Marc 2,6).

„Et omnium in synagoga oculi erant intendentes in eum" (Luc 4, 20).

„...ubi erat Ioannes baptizans primum" (Joh 10, 40).

Spostrzeżenie to ma znaczenie dla ustalenie możliwych stylistycznych konsekwencji zastosowania peryfrazy progresywnej, nie uzasadnia jednak hipotezy

${ }^{9}$ Szczegółowo analizę czasu i aspektu rozwijają m.in. I. Heim, Comments on Abusch's theory of tense, Amsterdam 1994; D. Abusch, Remarks on the State Formulation of de re Present Tense, „Natural Language Semantics" 5 (1997) 303-313; tenże, On Verbs and Time (rozprawa doktorska, University of Massachusetts Amherst), Massachusetts 1985; A. von Stechow, Tense in Intensional Contexts: Two Semantic Accounts of Abusch's Theory of Tense, Cambridge Mass. 1995; D. Abusch, On the Temporal Composition of Infinitives, w: Guéron - Lecarme (ed.), The Syntax of Time, s. 27-54; A. Kratzer, More structural analogies between pronouns and tenses, w: D. Strolovich A. Lawson (ed.), Proceedings of SALT VIII, Ithaca NY 1998, 92-110; A. von Stechow, On the Proper Treatment of Tense, Tübingen 1995; R. Bäuerle, Temporale Deixis - Temporale Frage, Tübingen 1979; A. von Stechow, The Janus Face of Aspect, Tübingen 2001; E. Gerö - A. von Stechow, Tense in Time: the Greek Perfect, w: R. Eckardt - K. von Heusinger - C. Schwarze (ed.), Words in Time: Diachronic Semantics from Diferent Points of View, Berlin - New York 2003, 251-294; I. Heim, Tense in compositional semantics: MIT lecture notes, Cambridge Mass. 1997; K. Kusumoto, Tense in embedded contexts (rozprawa doktorska, University of Massachusetts), Amherst 1999.

${ }^{10}$ Tak np. sądzi S. Eklund, The Periphrastic. Completive and Finite Use of the Present Participle in Latin, Uppsala 1970. Podobne wnioski formuluje się w odniesieniu do sytuacji greckiej, por. W.J. Aerts, Periphrastica, Amsterdam 1965.

11 Por. Aerts, Periphrastica, s. 52-75. 
o jej systemowo obcym charakterze. Warto zwrócić uwagę, że innowacja ta dotyka jedynie morfologicznej realizacji kompleksu semantycznego i pozostaje fakultatywna (syntetyczne praesens $\mathrm{i}$ imperfectum nie jest eliminowane jako realizacja PRES(lub PAST) + PROG).

Peryfraza progresywna jest w lacińskim materiale językowym dość rzadkim zjawiskiem; nawet w tekstach przywoływanych jako typowe przykłady na obecność tej struktury, zgramatykalizowana peryfraza jest zjawiskiem statystycznie nieistotnym. Ten stan rzeczy świadczy o braku rozpowszechnienia konstrukcji w języku; wiązać go należy zapewne $\mathrm{z}$ niestabilnością participium praesentis i jego eliminacją na rzecz ablativi gerundii. Peryfraza progresywna jest nadto strukturą znacznie bardziej wyspecjalizowaną z semantycznego punktu widzenia. Charakterystyczne, że w literaturze przedchrześcijańskiej dominują peryfrazy niewłaściwe, $\mathrm{z}$ p.p.a. przymiotnikowym lub znominalizowanym, np.:

„Mollis ac minime resistens ad calamitates perferendas mens eorum est"12.

„Virtutem [...] censuerunt ob eam rem esse laudandam, quod efficiens esset voluptatis"13.

Podobna sytuacja panuje w literaturze chrześcijańskiej: większość przykładów na p.p.a. + esse jest tego właśnie typu:

„Est et illud ad fidem pertinens, quod Plato bifariam partitur animam, per rationale et inrationale"14.

„Erit itaque pauper humilis ignobilis subiectus iniuriae et tamen omnia quae amara sunt perferens"15.

„Etenim revera est impium et sacrilegia cuncta transcendens..."16.

„Minora haec illo sunt et magnitudinis eius destruentia potestatem" ${ }^{17}$.

Peryfrazy niewłaściwe są strukturami predykacyjnymi, w których participium i podmiot tworzą tzw. Small Clause, a esse występuje jako copula ${ }^{18}$. Takie właśnie struktury stanowią punkt wyjścia dla powstania peryfraz zgramatykalizowanych; proces ten przebiega analogicznie do gramatykalizacji połączeń habere + participium perfecti passivi jako wykładnika praeteriti $i$, mutatis mutandis, połączeń habere + infinitivus jako wykładnika futuri; w obu wypadkach zachodzi uproszczenie struktury gramatycznej. Szczególnie bliska

12 Julius Caesar, De bello Gallico III 19, 6.

13 Cicero, De officiis III 116.

14 Tertullianus, De anima 16, 1, CCL 2, 802.

15 Lactantius, Institutiones VI 4, 11, CSEL 19, 491.

16 Arnobius, Adversus nationes I 23, 4-5, CSEL 4, 15.

17 Tamże II 46, 11-12, CSEL 4, 84.

18 Analizę semantyki takich struktur zob. np. u S. Rothstein, Fine-grained structure in the eventuality domain: the semantics of predicative adjective phrases and be, "Natural Language Semantics" 7 (1999) 347-420. 
jest analogia $z$ pierwszą $z$ wyżej wymienionych grup: także tutaj participium pierwotnie występuje $\mathrm{w}$ strukturze predykacyjnej. W przypadku połączeń p.p.a. + esse peryfraza progresywna nakłada precyzyjniejsze ograniczenia na typ czasowników mogących się w niej pojawić, wykluczając czasowniki stanu (co wynika z semantyki operatora progresywności); ograniczeń takich nie ma w przypadku struktur predykacyjnych, w których fraza czasownikowa dopuszcza daleko idącą elastyczność w interpretacji. W szeregu przypadków możliwe są obie analizy; ten stan rzeczy przyczynił się zapewne, jak słusznie przypuszcza W. Dietrich w odniesieniu do analogicznej struktury greckiej ${ }^{19}$, do łatwiejszej asymilacji peryfraz tekstu biblijnego. Konsekwencją stylistyczną jest możliwość zastosowania wszystkich rodzajów peryfraz z participium praesentis activi + esse dla ewokacji stylistycznej tekstu biblijnego. Tak jest np. w tekstach apokryficznych, gdzie są elementem celowej stylizacji wypowiedzi, jak na przykład:

„Ego autem servus tuus, tres dies sunt hodie trahentes me per omnes plateas et vicos huius civitatis"20.

W tekstach oryginalnych peryfraza wydaje się być rzadsza, w zależności od językowego konserwatyzmu i stylistycznych preferencji autora; nie pozwala to jednak na wnioskowanie o obcym charakterze konstrukcji lub jej zupełnej nieobecności w języku potocznym (poza ostrożną sugestią, że mimo postępującej gramatykalizacji nie jest konstrukcją bardzo częstą w języku mówionym). Niekiedy wyraźna jest imitacja języka biblijnego, jak na przykład:

„Et aperti sunt oculi eius et erat admirans cernensque magnalia Dei"”2l.

Odmienność struktury składniowej obu rodzajów peryfraz nie wyklucza zastosowania peryfraz niewłaściwych dla ewokacji języka biblijnego przez wykorzystanie efektu akumulacji i konwergencji w stylistycznie koherentnym kontekście. W taki sposób dokonuje się międzytekstowe nawiązanie u Lucyfera $z$ Cagliari, u którego p.p.a. w ogólności są rzadsze niż w tekście biblijnym (p.p.a. + esse jest zjawiskiem statystycznie mało istotnym, choć ze stylistycznego punktu widzenia bardzo ważnym). Ilustruje to porównanie zakresu występowania participium praesentis activi (we wszystkich funkcjach) u niektórych autorów ${ }^{22}$ :

${ }^{19}$ Por. W. Dietrich, Der periphrastische Verbalaspekt im Griechischen und Lateinischen, "Glotta" 51 (1973) 188-228, spec. 204 (z dalszymi przykładami); L. Rydbeck, Fachprosa, vermeintliche Volkssprache und Neues Testament, Uppsala 1967, 199.

20 Acta Andreae et Matthiae 28, ed. F. Blatt (Die lateinischen Bearbeitungen der Acta Andreae et Matthiae apud anthropofagos, Giessen 1930) s. 85, 16; por. Eklund, The Periphrastic, s. 64.

${ }^{21}$ Gregorius Turonesis, Historia Francorum VI 6, MGH Script. Mer. I 1, 175, 19; zob. Eklund, The Periphrastic, s. 73; M. Bonnet, Le latin de Grégoire de Tours, Paris 1890, 653.

22 Badanie przeprowadzone na próbach losowych. Poziom istotności $=0.05$. 


\begin{tabular}{|l|c|c|c|c|c|}
\hline & $\begin{array}{c}\text { formy } \\
\text { czasownikowe } \\
\text { ogólem }\end{array}$ & $\begin{array}{c}\text { participium } \\
\text { praesentis } \\
\text { activi }\end{array}$ & $\begin{array}{c}\text { udzial } \\
\text { p.p.a. }\end{array}$ & $\begin{array}{c}\text { błąd względny } \\
\text { oszacowania }\end{array}$ & $\begin{array}{c}\text { pólprzedział } \\
\text { ufnosci }\end{array}$ \\
\hline $\begin{array}{l}\text { Novum } \\
\text { Testamentum }\end{array}$ & 1234 & 134 & 0.1086 & 0.1598 & 0.0173 \\
\hline $\begin{array}{l}\text { Lucifer } \\
\text { Calaritanus, } \\
\begin{array}{l}\text { Moriundum } \\
\text { esse }\end{array}\end{array}$ & 765 & 56 & 0.0732 & 0.252 & 0.0184 \\
\hline $\begin{array}{l}\text { Vetus } \\
\text { Testamentum }\end{array}$ & 450 & 50 & 0.1111 & 0.2613 & 0.029 \\
\hline $\begin{array}{l}\text { Arnobius, } \\
\text { Adversus } \\
\text { nationes }\end{array}$ & 1123 & 43 & 0.0383 & 0.293 & 0.0112 \\
\hline $\begin{array}{l}\text { Peregrinatio } \\
\text { Egerice }\end{array}$ & 795 & 61 & 0.077 & 0.239 & 0.0184 \\
\hline
\end{tabular}

Dane te nie tylko potwierdzają opinię o znaczącym udziale p.p.a. wśród form czasownikowych w tekstach biblijnych, ale także wskazują na rolę kontekstu przesądzającego o interpretacji stylistycznej. Na uwagę zasługuje znacznie niższy udział p.p.a. w tekście Peregrinatio, niż w tekście biblijnym lub u Lucyfera, potwierdzający tendencję do eliminacji tej formy.

Znaczenie kontekstu dla stylistycznej interpretacji omawianej peryfrazy wyraźnie widoczne jest u Lucyfera. Bezpodstawne byłoby przypuszczenie, że w tekstach Lucyfera znajduje odbicie stan językowy sermo cotidianus - nic nie potwierdza tak daleko posuniętego rozpowszechnienia peryfrazy. Zapewne, można to zjawisko częściowo przypisać zasadzie variatio i osobistej predylekcji Lucyfera; to jednak nie wyjaśnia w stopniu wystarczającym względnej częstości peryfraz. Nie jest, jak się zdaje, przypadkiem zbieżność używana przez Lucyfera i thumaczy tekstów biblijnych, odnotowana przez Eklunda, dodającego: ,apparently he [= Lucifer] picked up a strange construction and made it a feature of his style"23. Skąd jednak taka decyzja stylistyczna, zastanawiająca zwłaszcza wobec wstrzemięźliwości innych autorów chrześcijańskich wobec tego typu konstrukcji? Odpowiedzi szukać należy w ogólnej strategii stylistycznej Lucyfera, ściśle związanej ze sposobem modelowania sytuacji i polemiczną intencją tekstu, służącej profetycznej stylizacji wypowiedzi. Z zabiegami stylistyczno-językowymi skorelowane są stosowane przez Lucyfera technika intertekstualna i zastosowanie na szeroką skalę cytatów biblijnych, a w przypadku Moriundum esse także $\mathrm{z}$ innych tekstów:

„... nihil iudico ad me pertinere, alitesne an canes corpus meum lanient" ${ }^{24}$,

${ }^{23}$ Eklund, The Periphrastic, s. 68.

${ }^{24}$ Lucifer Calaritanus, Moriundum esse pro Dei Filio 14, 19-20, CCL 8, 296. 
„Heu, terra ignota canibus data praeda Latinis alitibusque iaces"25.

„Stat semper nempe gladii tui acies extricta parata Christianorum neci"26.

"Stat ferri acies mucrone corusco stricta, parata neci" ${ }^{27}$.

Podstawową rolę $\mathrm{w}$ interpretacji tekstu pełnią jednak i inne nawiązania: za kluczowe uznać można dwa z nich - do Katylinarek Cycerona i Apologetyku Tertuliana:

"Quousque tandem abuteris dei patientia, Constanti? "28

"Quousque tandem abutere, Catilina, patientia nostra? "29

„Semper Christiani vobis tyrannis in persecutione perversa quaestione torquemur. Quo enim genere nocentes coguntur ad confitendum, eo nos compellimur modo ad Christum unicum verissimum filium dei negandum" ${ }^{\text {30. }}$.

„Sed nec in isto ex forma malorum iudicandorum agitis erga nos, quod ceteris negantibus tormenta adhibetis ad confitendum, solis Christianis ad negandum" 31 .

Oba zanurzone są w bardzo specyficznym kontekście stylistycznym, Kunstsprache silnie stylizowanej na profetyczny język tekstów świętych. Wskazanie przynależności do takiej tradycji literackiej jest w przypadku Lucyfera czymś więcej niż tylko prostą konsekwencją wyboru stylistycznego lub manifestacją światopoglądową: wiąże się to z jednoznacznym modelowaniem wspólczesnej sytuacji historycznej i roli podmiotu tekstowego przez odesłanie do modelu biblijnego. Przytoczone wyżej nawiązania pozwalają sprecyzować naturę tej relacji: wynikające $\mathrm{z}$ nich wprost zestawienie Konstancjusz - Katylina (a więc hostis domesticus) i Konstancjusz - antistes imperii Romani (więc obrońca fałszywych przekonań i prześladowca chrześcijan) jest konstrukcyjną osią pamfletu Lucyfera. Liczne parafrazy wcześniejszych autorów chrześcijańskich współgrają z taką właśnie interpretacją i ją potwierdzają, jak na przykład:

„... «sed defendenda sunt», inquiunt, «suscepta publice sacra». O quam honesta voluntate miseri errant!"32.

„Tantam perseverantiam cernens Christianorum, 'defendenda est', inquis, 'et a me semel susceptum Arrianum dogma'; dicis talia honesta voluntate errans. Sentis enim nihil esse in rebus humanis religione praestantius eamque summa vi oportere defendi" ${ }^{33}$.

\footnotetext{
${ }^{25}$ Vergilius, Aeneis IX 485-486.

26 Lucifer Calaritanus, Moriundum esse pro Dei Filio 8, 53-54, CCL 8, 283.

27 Vergilius, Aeneis II 333-334.

28 Lucifer Calaritanus, Moriundum esse pro Dei Filio 12, 38, CCL 8, 292.

29 Cicero, In Catilinam I 1.

${ }^{30}$ Lucifer Calaritanus, Moriundum esse pro Dei Filio 3, 26-29, CCL 8, 270.

31 Tertulianus, Apologeticus 2, 10, CCL 1, 89.

32 Lactantius, Divinae institutiones V 19, 20-21, CSEL 19, 465.

${ }^{33}$ Lucifer Calaritanus, Moriundum esse pro Dei Filio 11, 37-41.
} 
Peryfrazy z p.p.a., zarówno niewłaściwe, jak i progresywne, są jednym z elementów celowej strategii tekstowej Lucyfera, nieprzypadkowo deklarującego, jak zaznaczałem: „Nos sumus tantum sacras scientes litteras”. Nie sposób analizować języka Lucyfera w oderwaniu od pozostałych płaszczyzn tekstu i jego otoczenia (w sensie technicznym); nieuniknione jest bowiem wtedy wikłanie się w sprzeczności, których konsekwencją są wartościujące sądy („eius in scribendo stylus omnino rudis et pene barbarus" ${ }^{34}$ ), świadczące o całkowitym niezrozumieniu tekstu i autora: „Sein ganzes Auftreten trägt den Stempel jenes entlegenen Winkels der Zivilisation, in dem er zu Hause war: eine wenig kultivirte Erscheinung, ein ungehobelter Bursche ohne Manieren, soeben der Wildnis entsprungen, würden wir sagen"35. Uderzająca częstość peryfraz z p.p.a. w pismach Lucyfera jest efektem celowego wykorzystania jako środka stylistycznego elementu traktowanego jako typowego dla języka biblijnego. Przypuszczenie to znajduje potwierdzenie $w$ fakcie, że omawiana peryfraza jest wykorzystywana w tekstach apokryficznych oraz w imitatio języka biblijnego. Równocześnie jednak nie ma podstaw do odmówienia peryfrazie progresywnej rdzennie łacińskiego statusu, niezależnie od stylistycznie nacechowanego charakteru.

\section{PROGRESSIVE PERIPHRASIS AND TEXTUAL STRATEGIES Lucifer of Cagliari, Moriundum esse pro Dei Filio:}

(Summary)

One of the most striking features of Lucifer's style is his frequent usage of a periphrastic structure participium praesentis activi + esse. The paper proposes that there is a clear semantic distinction between this construction and synthetic verbal forms. Stylistic and interpretive consequences of Lucifer's usage follow from a comparison with other authors and transtextual gestures which determine a proper contextualization of such structures.

${ }^{34}$ Por. J. Coleti, Praefatio, PL 13, 736C.

35 Berkhof apud G. Diercks, Introduction, w: G. Diercks (ed.), Luciferi Calaritani opera quae supersunt, CCL 8, s. LXXI, n. 2. 